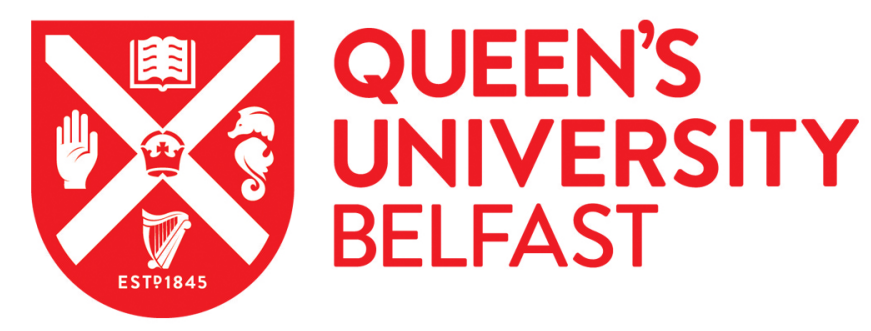

\title{
Propionibacterium acnes wound contamination at the time of spinal surgery
}

McLorinan, G. C., Glenn, J., McMullan, M. G., \& Patrick, S. (2005). Propionibacterium acnes wound contamination at the time of spinal surgery. Clinical Orthopaedics and Related Research, 437(437), 67-73.

Published in:

Clinical Orthopaedics and Related Research

Queen's University Belfast - Research Portal:

Link to publication record in Queen's University Belfast Research Portal

\section{General rights}

Copyright for the publications made accessible via the Queen's University Belfast Research Portal is retained by the author(s) and / or other copyright owners and it is a condition of accessing these publications that users recognise and abide by the legal requirements associated with these rights.

Take down policy

The Research Portal is Queen's institutional repository that provides access to Queen's research output. Every effort has been made to ensure that content in the Research Portal does not infringe any person's rights, or applicable UK laws. If you discover content in the Research Portal that you believe breaches copyright or violates any law, please contact openaccess@qub.ac.uk. 


\title{
Propionibacterium acnes Wound Contamination at the Time of Spinal Surgery
}

\author{
Gregory C. McLorinan, MRCS*; Josephine V. Glenn, PhD*; Michael G. McMullan, MRCS†; \\ and Sheila Patrick, PhD*
}

Bacteria of the normal skin microbiota such as Propionibacterium acnes and coagulase-negative staphylococci often are dismissed as contaminants when detected in clinical samples. Propionibacterium acnes is described as a cause of spinal infection and more recently has been linked to sciatica. To date no researchers formally have examined the incidence of bacterial wound contamination during spinal surgery. Surgical specimens were removed from 79 patients having spinal surgery for analysis using agar culture detection, broth enrichment, and immunofluorescence microscopy. Bacteria were identified in $29.1 \%$ of skin samples, $21.5 \%$ of tissue samples and $16.5 \%$ of washings retrieved from operative wounds. Propionibacterium acnes was identified more frequently than Staphylococcus spp in each of the three sample types. Bacteria were detected using enrichment in $9(11 \%)$ patients and using fluorescence microscopy in $15(19 \%)$. The results of immunofluorescence microscopy suggest that Propionibacterium acnes detected in wounds originates from patient skin. Bacteria from contaminated wounds appeared as single cells using fluorescence microscopy; however previous work shows that bacteria from infected hip prosthesis are observed as large aggregates. Therefore, it is suggested that immunofluorescence microscopy is a useful tool to help discriminate between surgical contamination and infection.

Level of Evidence: Diagnostic study, Level I (prospective study). See the Guidelines for Authors for a complete description of levels of evidence.

From the *Department of Microbiology, School of Medicine, Queen's University, and the †Fractures Department, The Royal Victoria Hospital, Belfast, UK. One or more of the authors received funding from The Royal College of Surgeons of England, The Wishbone Trust and The European Social Fund. Each author certifies that his or her institution has approved the human protocol for this investigation, that all investigations were conducted in conformity with ethical principles of research, and that informed consent was obtained.

Correspondence to: Sheila Patrick, PhD, Department of Microbiology, School of Medicine, Queen's University, Grosvenor Road, Belfast, BT12 6BN, UK. Phone: 44(0)2890 632512; Fax: 44(0)2890 635024; E-mail: s.patrick@qub.ac.uk.

DOI: 10.1097/01.blo.0000175716.76247.81
Propionibacterium acnes is an anaerobic gram-positive diphtheroid bacterium that forms part of the resident skin microbiota. Propionibacterium acnes has two distinct phenotypes, known as Types I and II. ${ }^{13}$ The phenotypes are distinguished by serologic agglutination tests and cell wall sugar analysis. Propionibacterium acnes has become increasingly recognized as an important pathogen not only in acne, ${ }^{3,11,21}$ but in medical-device, ${ }^{2}$ dental, ${ }^{6}$ ocular, ${ }^{20}$ and neurosurgical infections, ${ }^{10}$ and also has been linked to synovitis-acne-pustulosis-hyperostosis-osteitis (SAPHO) syndrome $^{14}$ and even sarcoidosis. ${ }^{8}$ It has been reported previously that there is a strong association between $\mathrm{P}$. acnes and failed prosthetic hip implants. ${ }^{23,24}$

Despite the increasing recognition of $\mathrm{P}$. acnes as a pathogen, its presence in clinical samples, especially those from orthopaedic sources, might result from simple contamination. For example, sampling of clean orthopaedic wounds has shown a relatively high proportion of contamination by P. acnes, ${ }^{7}$ whereas salvaged intraoperative blood from patients having primary hip arthroplasty has revealed contamination by P. acnes and Staphylococcus spp. $^{25}$

Propionibacterium acnes also is associated with spinal infection. It has been isolated in cases of spinal osteomyelitis and discitis. ${ }^{5,9,16}$ Stirling and colleagues suggested a possible link between P. acnes and sciatica. ${ }^{22}$ Despite the apparent association between P. acnes and the spine no study to date quantifies the incidence of intraoperative wound contamination during spinal surgery.

The primary aim of this study is to ascertain the level of bacterial contamination of wound samples during spinal surgery. As well as identifying the principal bacteria involved in spinal wound contamination, possible association between the site of surgical incision and the incidence of bacterial contamination is examined. The usefulness of alternative methods to bacterial detection using agar culture, including the use enrichment broth and immunofluorescence microscopy (IFM) is assessed. Specifically we hoped to be able to demonstrate that immunofluorescence 
microscopy permits the distinction between contamination and infection.

The study also describes a technique used to quantify P. acnes at different sites of the human body and also to identify the P. acnes phenotypes at those sites. The phenotypes of $\mathrm{P}$. acnes identified in surgical wounds are compared to the phenotypes identified on the surface of healthy skin to help identify the possible origin of P. acnes in the surgical wound.

\section{MATERIALS AND METHODS}

Surgical material was removed from 79 consecutive patients having spinal surgery for a range of spinal conditions in Belfast between August 2002 and August 2004. Surgical material was examined for the presence of bacteria by means of agar culture, broth enrichment and immunofluorescence microscopy. A further group of 10 healthy volunteers had skin swabs taken for quantification of $\mathrm{P}$. acnes at different skin sites for comparison. The study was approved by the local ethical committee.

Surgical specimens were retrieved from 79 patients: 46 (58.2\%) men and 33 (41.8\%) women, with indications for surgery as follows: $50(63.3 \%)$ having discectomy for sciatica, 12 $(15.2 \%)$ having laminectomy for disc degeneration, 10 (12.7\%) having anterior correction of scoliosis, four $(5.0 \%)$ having fixation of fracture caused by trauma, and three $(3.8 \%)$ having resection of vertebral tumor. Metallic implants were inserted in all patients in the scoliosis, fracture, and tumor groups. Seven (58.3\%) patients in the degeneration group had metallic implants inserted, two (16.6\%) had carbon fiber implants inserted and three $(25.0 \%)$ had no implant inserted. No implants were used in the sciatica group. There were $56(70.9 \%)$ lumbar incisions, 13 $(16.5 \%)$ thoracic or thoracoabdominal, six $(7.6 \%)$ anterior cervical and four $(5.1 \%)$ midline abdominal incisions. Sixty-eight $(86.1 \%)$ were primary procedures, $10(12.9 \%)$ were revision surgeries, and the procedure status of one $(1.3 \%)$ patient was not known. Of the 10 patients who had revision surgeries seven patients had removal of recurrent disc prolapse and three had already had previous discectomy and currently were having laminectomy for spinal stenosis. Sixteen (20.3\%) patients had previous spinal cannulation (epidural/intradural injection). Two $(2.5 \%)$ had a previous acne history, five $(6.3 \%)$ were unsure, and $72(91.1 \%)$ had no previous acne history. Four $(5.1 \%)$ patients received no prophylactic antibiotic, one (1.3\%) received cefadrine, four $(5.1 \%)$ received erythromycin, 29 (36.7\%) received cephamandole, and 41 (51.9\%) received cefuroxime. Patients were excluded from the study if infection was suspected based on clinical criteria. All surgery was done in a laminar airflow theater.

Patients' skin in all cases was prepared with Betadine (Seton Healthcare, Oldham, England) antiseptic solution. The following samples were obtained from all patients: a sample of skin (approximately $1 \mathrm{~mm} \times 5 \mathrm{~mm} \times 3 \mathrm{~mm}$ ) was removed from the wound edge and a piece of tissue (approximately $3 \mathrm{~mm} \times 3 \mathrm{~mm}$ $\times 3 \mathrm{~mm}$ ) was removed from within the wound. In addition, sterile saline $(10 \mathrm{~mL})$ was poured into the base of the wound and was allowed to collect; then $10 \mathrm{~mL}$ of this fluid was aspirated for culture.

The skin sample was pulped by vortex mixing with glass beads in $1 / 4$ strength Ringer's solution containing $0.05 \mathrm{~g} / \mathrm{l} \mathrm{L}$ cysteine (QSR). Wound tissue fragments in $5 \mathrm{~mL}$ of QSR in universal bottles (International Scientific Supplies Limited, Bradford, UK) were exposed to ultrasonication for 5 minutes at $50 \mathrm{kHz}$ in an ultrasound bath (Decon, 150W Model FS200B, Decon Laboratories Limited, Hove, UK). Skin, wound, and wash samples ( $0.5 \mathrm{~mL}$ volumes) were spread plated onto blood agar (BA; Oxoid Ltd., Basingstoke, UK) and anaerobic blood agar (ABA; Oxoid Ltd., Hampshire, England) plates in triplicate and incubated either aerobically or anaerobically for 14 days as previously described. ${ }^{24}$ Agar culture was considered positive if bacteria were cultured on two of three aerobic or two of three anaerobic agar plates. Wound samples $(0.5 \mathrm{~mL})$ also were added to Robertson's cooked meat broth enrichment culture (Oxoid Ltd.), incubated for 3 weeks, plated onto BA and ABA, and these plates were examined after a further week. For the purposes of analysis, agar culture was considered the reference standard with which broth enrichment was compared. Stringent aseptic technique was adhered to at all times and any open sample processing was done within the confines of an anaerobic workstation (MACS MG 1000, Don Whitley Scientific, Shipley, UK) in which a gas mixture $\left(80 \% \mathrm{~N}_{2}, 10 \% \mathrm{CO}_{2}\right.$, and $\left.10 \% \mathrm{H}_{2}\right)$ was bubbled continuously through glutaraldehyde (2\%) to prevent aerial contamination by bacteria. Pure cultures of bacteria were identified using commercially available biochemical test galleries (API, BioMèrieux, Basingstoke, UK).

A modification of the immunofluorescence microscopy (IFM) procedure described by Tunney et al was done on the wound diluents. ${ }^{23}$ Three P. acnes antibodies were used. Antibody QUB PaIII reacts with a common antigen present on P. acnes Types 1 and 2. Antibodies QUB Pa1 and QUB Pa2 react with P. acnes Types 1 and 2 respectively. QUB PA3 cross-reacts with some Propionibacterium granulosum, Actinomyces naeslundii and A. israelii isolates. These bacteria were not, however, identified in any specimen using biochemical tests. QUB Pa1 and QUB Pa2 do not react with other propionibacterium species or a range of other related bacteria including the aerobic coryneforms.

Wound wash samples $(1 \mathrm{~mL})$ were centrifuged at $16,100 \mathrm{~g}$ for 15 minutes. The supernatant was removed, leaving a small pellet. The pellet was re-suspended in $40 \mu \mathrm{L}$ of phosphate buffered saline (PBS; $1.061 \mathrm{~g} \mathrm{Na}_{2} \mathrm{HPO}_{4}, 0.389 \mathrm{~g} \mathrm{NaH} \mathrm{PO}_{4} .2 \mathrm{H}_{2} \mathrm{O}$ and $8.5 \mathrm{~g}$ $\mathrm{NaCl}$ per liter of $\left.\mathrm{H}_{2} \mathrm{O}\right)$. Samples $(20 \mu \mathrm{L})$ then were applied to multiwell slides, air-dried, and fixed in $100 \%$ methanol for 10 minutes at $-20^{\circ} \mathrm{C}$. The fixed material was incubated for $45 \mathrm{~min}-$ utes at $37^{\circ} \mathrm{C}$ with either undiluted hybridoma cell culture supernatant $(30 \mu \mathrm{L})$ containing P. acnes reactive monoclonal antibody (QUB Pa3) or an appropriate dilution of rabbit antiStaphylococcus spp polyclonal antiserum $(30 \mu \mathrm{L})$. The primary antibody was gently washed off and the slide immersed in a $0.01 \mathrm{M}$ PBS for 15 minutes. Goat antimouse or goat antirabbit flourescein-isothiocyanate conjugate (FITC, Sigma, Poole, $\mathrm{UK})$, at 1:100 dilution in PBS $(30 \mu \mathrm{L})$ containing $0.02 \%$ (volume/volume) Evans Blue (Sigma, Poole, UK) was applied to 
each well. After a further 45-minute incubation period, the slides were again washed in PBS, mounted in glycerol-PBS containing an anti-photobleaching agent (Citifluor, Agar Scientific Ltd, Stansted, UK) and examined using a Leitz Dialux 20 fluorescence microscope (Leitz, Wetzler, Germany).

When P. acnes was identified from more than one site of any patient, up to three separate colonies from each site were examined by IFM using monoclonal antibodies that react with either Type 1 (QUB Pa1) or Type 2 (QUB Pa2) P. acnes. This permitted the typing of $\mathrm{P}$. acnes isolated from surgical specimens.

Skin swabs were taken from 10 healthy volunteers. Sites representing areas of common orthopaedic incision including skin over the lateral aspect of the hip, lateral aspect of the chest wall, neck, lumbar spine, and below the umbilicus were swabbed using a sterile paper template $\left(10 \mathrm{~cm}^{2}\right)$. The forehead also was swabbed for comparison. The swab tip was vortex agitated in QSR $(1.0 \mathrm{~mL})$ and $0.5 \mathrm{~mL}$ was used to make a series of 10-fold dilutions in QSR. Each dilution was spread plated in triplicate onto TYG agar plates $(20 \mathrm{~g} / \mathrm{L}$ tryptone, $10 \mathrm{~g} / \mathrm{L}$ yeast extract, $5 \mathrm{~g} / \mathrm{L}$ glucose with $1 \%$ agar) containing $2 \mu \mathrm{g}$ per $\mathrm{mL}$ furazolidone (Sigma, Poole, UK) to inhibit staphylococcal growth. ${ }^{21}$ Plates were incubated anaerobically for 4 days at $37^{\circ} \mathrm{C}$ and the number of colonies was recorded. Immunoreaction was done as previously described, with minor modification. ${ }^{19}$ In brief, nitrocelluose was blocked with $0.01 \mathrm{M}$ PBS containing $0.05 \%$ (volume/volume) Tween-20 (PBS-Tween) and 5\% (weight/volume) nonfat milk powder (Marvel, Premier brands, Spalding, UK). After washing with PBS-Tween, the nitrocellulose was incubated in undiluted MAb-containing supernatant (QUB Pa1 or QUB Pa2). The nitrocelluose then was washed in PBS-Tween before incubation with a goat anti-mouse IgG (whole molecule) alkaline phosphatase conjugate (Sigma, Poole, UK). Bound MAbs were detected using an alkaline phosphatase conjugate substrate kit, containing nitroblue tetrazolium and 5-bromo-4-chloro-3-indolyl phosphate (Biorad Laboratories Ltd., Hercules, CA). The number of each subtype of P. acnes then was counted.

The incidence of bacterial contamination in each type of wound was compared using Fischer's exact test. A significance level of 0.05 was used.

\section{RESULTS}

Bacteria most frequently were cultured from skin samples $(29.1 \%)$ and less frequently from wound tissue $(21.5 \%)$ and wound wash (16.5\%) (Fig 1). Staphylococcus aureus was detected in the skin, wound tissue and wound wash of one patient. All other Staphylococcus spp identified were coagulase-negative staphylococci (CoNS). We found no association between wound type (lumbar or nonlumbar) and either detection of or particular bacteria in the skin samples or wound wash using agar. We also found no association between wound type and the presence of P. acnes. Staphylococcus spp was detected more frequently in nonlumbar wounds than other sites $(\mathrm{p}=0.004)$.
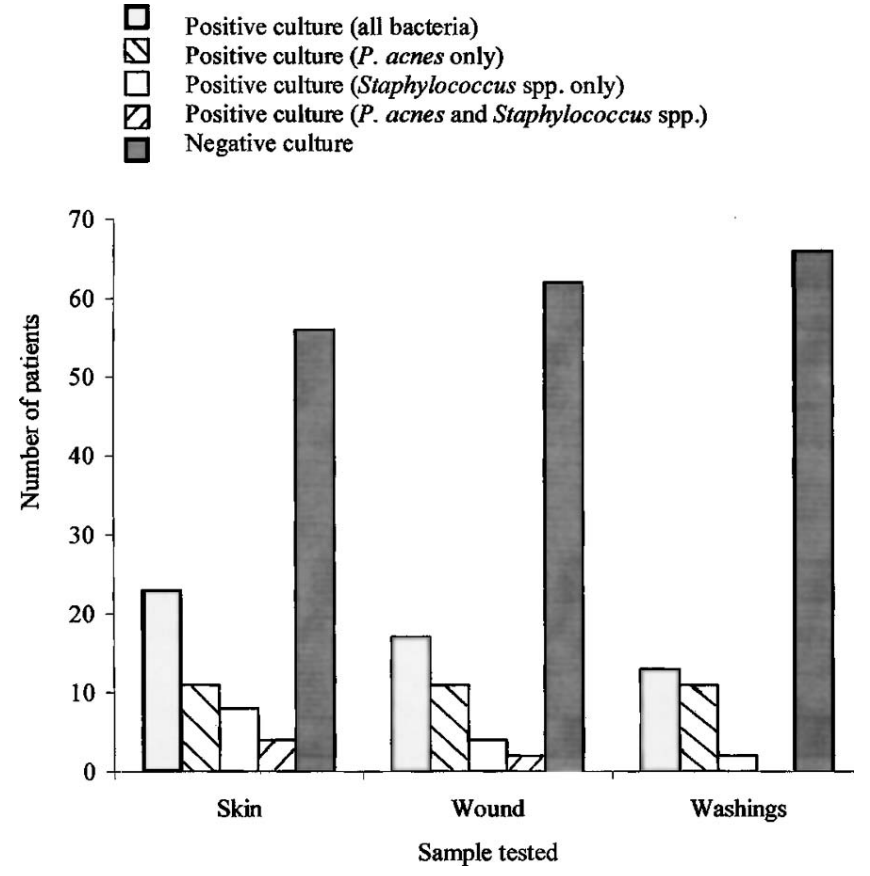

Fig 1. A histogram shows the bacteria detected in surgical specimens (skin, wound tissue, and wound washings) retrieved from patients having spinal surgery.

Seventeen $(25.0 \%)$ of patients having primary surgery had positive cultures from wound tissue and $13(19.1 \%)$ had positive cultures from wound washings. No patients having revision surgery had positive cultures from wound tissue or wound wash. This also was the case for the patient of whom the revision status was not known. There was no significant difference between revision status and positive culture from tissue or positive culture from wound wash.

Nine (11.4\%) broth samples from the 79 patients had a positive culture. Propionibacterium acnes was cultured in eight $(88.9 \%)$ of positive broth cultures and Staphylococcus spp was cultured in the remaining broth (11.1\%). No enrichment broth contained both P. acnes and Staphylococcus spp. Enrichment broth was $57.7 \%$ specific and $96.1 \%$ sensitive for the detection of $\mathrm{P}$. acnes and $25.0 \%$ sensitive and $99.0 \%$ specific for the detection of Staphylococcus spp.

The pure cultures isolated from 14 patients who were culture positive for P. acnes in the skin and other areas of the wound including 10 lumbar wounds, three anterior cervical wounds, and one abdominal wound, were typed using monoclonal antibodies specific for Type 1 and Type 2 P. acnes. The mean number of P. acnes colonies tested per patient was 11 colonies (range, 2-18 colonies per patient). In eight patients, only Type $1 \mathrm{P}$. acnes was detected and in four patients, only Type 2 P. acnes was detected. 
Only two of 14 patients had a mixture of Type 1 and Type 2 P. acnes. Mixed P. acnes populations were detected in one lumbar and one anterior cervical wound.

Fifteen $(19.0 \%)$ of 79 wound tissue samples examined using IFM had visible bacteria. P. acnes was the only bacterium observed in nine $(60 \%)$ immunofluorescence positive samples. P. acnes was detected with Staphylococcus spp using IFM in a further three (20\%) samples. Staphylococcus spp was the only bacterium detected using IFM in $3(20 \%)$ cases.

Five of 14 (35.7\%) wound tissue samples that had positive agar cultures for P. acnes also were IFM positive. Seven of $65(89.2 \%)$ of wound tissue samples that had negative agar culture were IFM positive. Compared with agar culture of bacteria, IFM for the detection of P. acnes in this setting had a sensitivity value of $35.7 \%$, specificity $89.2 \%$, positive predictive value (PPV) $41.6 \%$, negative predictive value (NPV) $86.6 \%$.

One of $10(10 \%)$ wound samples that were agar-culture positive for Staphylococcus spp also was IFM positive. Five of $69(7.2 \%)$ wound tissue samples that were agarculture negative were IFM positive. Immunofluorescence microscopy had a sensitivity value of $10 \%$, specificity 92.8\%, PPV 16.6\%, and NPV $87.7 \%$.

When bacteria were detected, they typically appeared as single cells (Fig 2) using fluorescence microscopy whereas bacteria detected in cases of prosthetic hip loosening appeared as large aggregates (Fig 3).

In the 10 healthy volunteers the area of skin most heavily colonized by P. acnes was the neck followed by the forehead, the lumbar spine, the abdomen, the chest, and the hip (Table 1). The forehead, neck and lumbar spine contained approximately $10^{2}$ to $10^{3}$ as many bacteria as the other sites. The lumbar spine had $4 \times 10^{2}$ as many P. acnes per $\mathrm{cm}^{2}$ as the hip. Colonies were lifted from the agar onto nitrocellulose and reacted with either Type 1 or Type 2 monoclonal antibodies. In all sites sampled, P. acnes was detected most frequently in mixed Type 1 and Type 2 populations (Fig 4). The neck and the hip were the sites with the highest number of mixed populations. The forehead was the site most likely to contain only Type $1 \mathrm{P}$. acnes. The chest was the only site to contain an exclusively Type $2 \mathrm{P}$. acnes population.

\section{DISCUSSION}

The purpose of this study was to determine the incidence of intraoperative wound contamination during spinal surgery and to identify the most likely source of contaminating organisms. We show that wound contamination during spinal surgery occurs relatively frequently by bacteria that form part of the normal skin microbiota. To date, there has been no formal examination of the incidence of wound
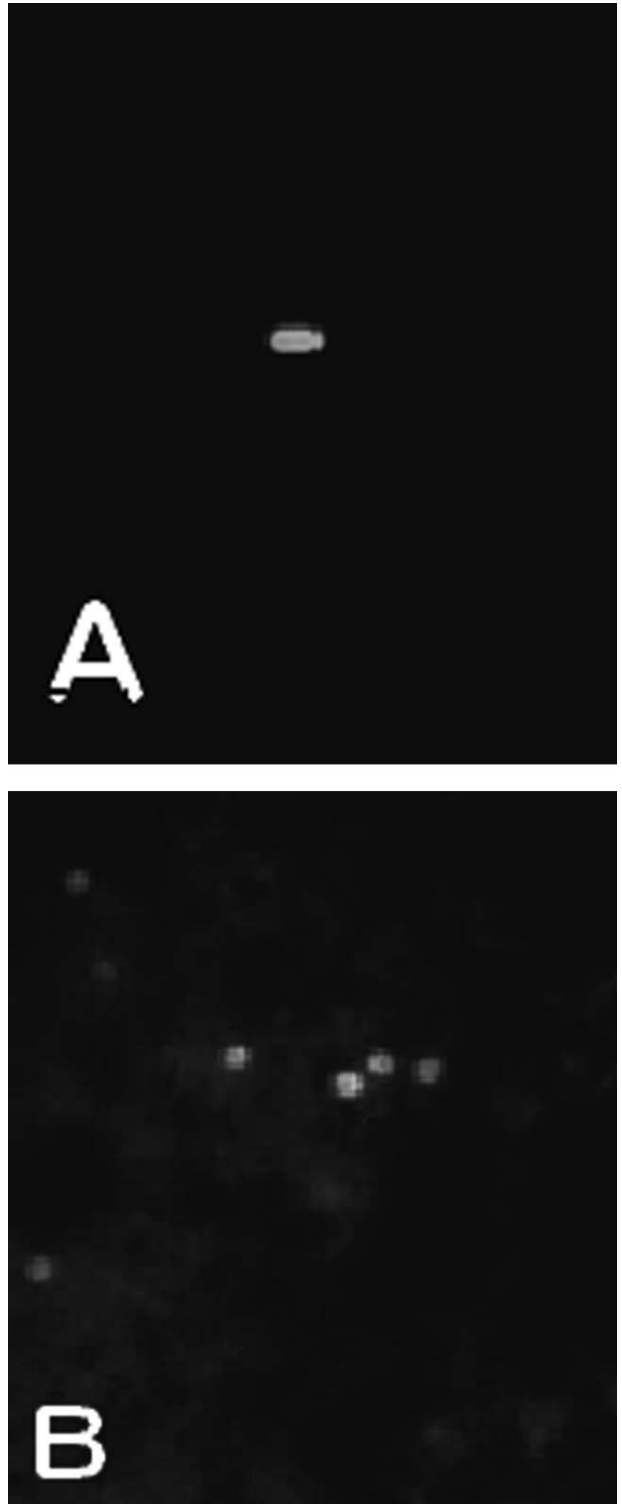

Fig 2A-B. Immunofluorescence micrographs show (A) P. acnes and (B) Staphylococcus spp detected in a contaminated spinal wound.

contamination during spinal surgery. Other authors also have shown the presence of normal skin microbiota in surgical wounds. Padgett et al ${ }^{18}$ found that $30 \%$ of revision hip arthroplasty wounds had positive bacterial cultures. The predominant organisms identified were principally S. epidermidis and P. acnes, as was the case in the current study. Dietz et al, ${ }^{7}$ who sampled clean orthopaedic wounds (excluding total joint replacements) for the presence of bacteria, found that as many as $58 \%$ of wound samples had positive cultures and that the predominant bacteria isolated were also skin microbiota. Wollinsky et $\mathrm{al}^{25}$ had similar 

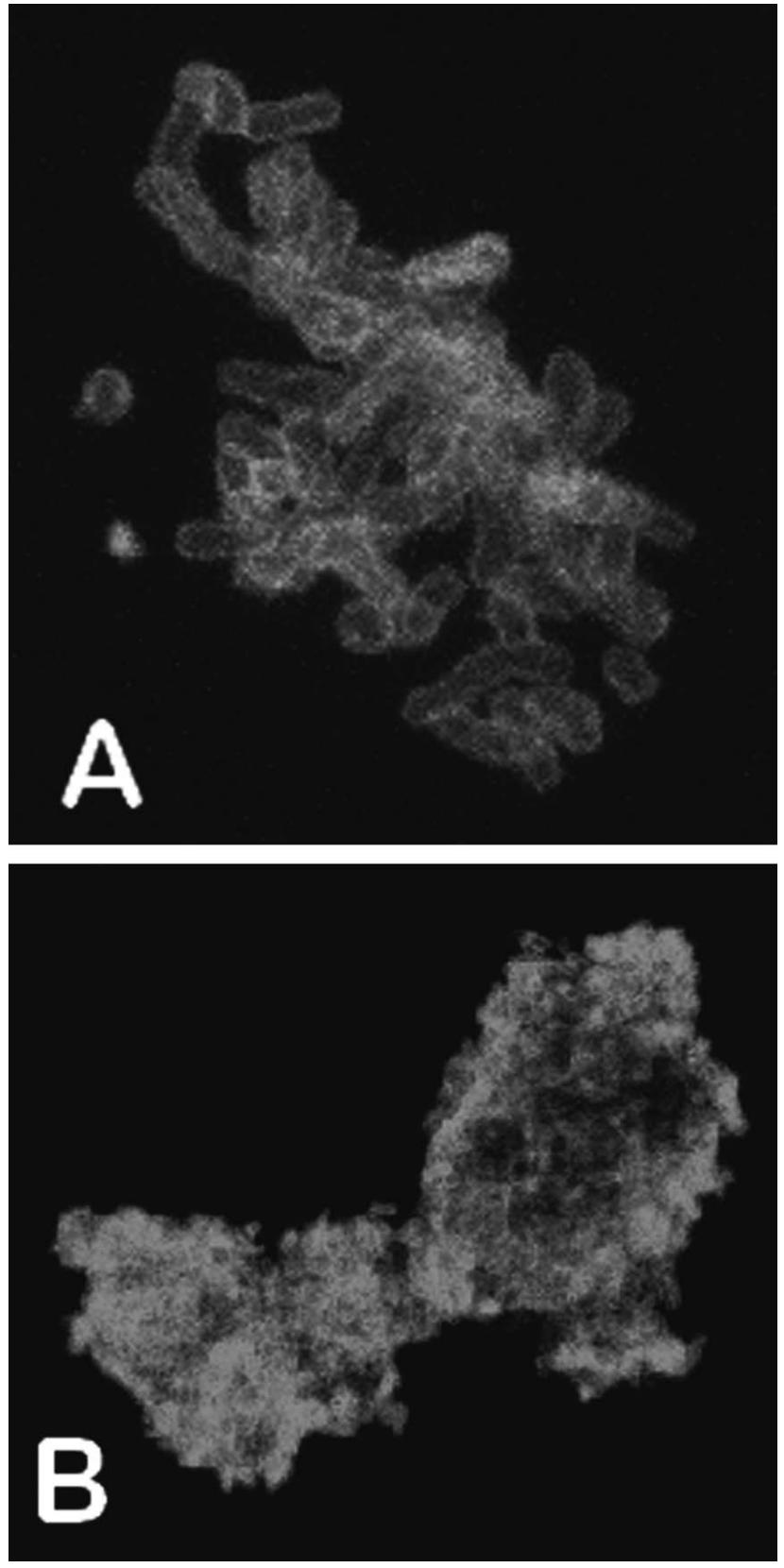

Fig 3A-B. Immunofluorescence micrographs show (A) P. acnes and (B) Staphylococcus spp detected in material dislodged by ultrasound from a failed hip replacement prosthesis (note large aggregates).

findings when they salvaged intraoperative blood from the surgical wounds was screened for the presence of bacteria. The incidence of positive cultures from wound tissue samples in the current study is slightly lower than that described in the literature (Table 2). This perhaps is explained by the fact that the majority of patients in the current study received antibiotics before samples were taken whereas no antibiotics were administered before samples were taken in the other studies. Stirling et $\mathrm{al}^{22}$ make no reference to antibiotic prophylaxes in their study. The studies by Padgett et al, ${ }^{18}$ Wollinsky et al, ${ }^{25}$ and Dietz et $\mathrm{al}^{7}$ show that CoNS are identified more frequently from orthopaedic wounds than P. acnes. ${ }^{7,18,25}$ In the current study P. acnes was detected more frequently than CoNS. Stirling et $\mathrm{al}^{22}$ also detected $\mathrm{P}$. acnes more frequently from spinal surgical specimens and in the study by Dietz et al. ${ }^{7}$ P. acnes was identified as frequently as CoNS when only spinal wounds are considered. ${ }^{7,22}$ The current study did not identify previous spinal injection as a risk factor for positive culture from a wound. This also was the finding of Stirling et al. ${ }^{22}$ Broth enrichment culture in our experience did not improve the detection of bacteria from surgical specimens. Broth enrichment often is used to improve the detection of bacteria. Dietz et $\mathrm{al}^{7}$ demonstrated that enrichment improved bacterial detection by $15 \% .^{7}$ It is possible in the current study that agar culture detection was more sensitive than broth enrichment because of the strict adherence to anaerobic conditions during transportation of samples, or the enrichment broth used might not be an ideal medium for the bacteria present in samples.

There were high numbers of cutaneous P. acnes particularly on the forehead, neck and lumbar spine area the skin of healthy volunteers. McGinley et al, ${ }^{15}$ in a study of the regional variations on cutaneous propionibacteria, also found also found high levels of P. acnes in the forehead and other sebum rich areas. ${ }^{15}$ To date no authors have examined specifically the phenotypes or numbers of $\mathrm{P}$. acnes areas used to site orthopaedic incisions.

Bacterial contamination of the surgical wound is thought to occur because of aerial contamination of the wound, ${ }^{4}$ or contamination from the patients own skin. Using fluorescence microscopy to identify the phenotypes of P. acnes found in operative samples we hoped this would enable the determination of origin of the P. acnes detected.

When fluorescence microscopy was compared with the colony lift method it was noted that only one of $10(10 \%)$ lumbar wounds contained Type 1 and Type 2 P. acnes. This was in contrast with the P. acnes populations detected in unprepared lumbar skin from healthy volunteers, 7 of 10 (70\%) who had a mixture of Type 1 and Type 2 P. acnes. The source of the P. acnes identified in the patient's wound is most likely to be the patient's own skin and this is supported by the fact that that the P. acnes phenotype identified in the surgical wound was the same as the P. acnes phenotype identified from the operative skin sample. Although the sample sizes are relatively small and the methods used are not directly comparable, it is possible that antiseptic solution may alter the natural balance of the P. acnes population in normal skin. Further work into the 
TABLE 1. Comparison of P. acnes Populations at Different Skin Sites in Healthy Volunteers*

\begin{tabular}{|c|c|c|c|c|c|c|c|c|}
\hline $\begin{array}{l}\text { Subject } \\
\text { Number }\end{array}$ & $\begin{array}{c}\text { Age } \\
\text { (years) }\end{array}$ & $\begin{array}{c}\text { Sex } \\
\text { (M/F) }\end{array}$ & $\begin{array}{l}\text { Forehead } \\
\left(\mathrm{cfu} / \mathrm{cm}^{2}\right)\end{array}$ & $\begin{array}{c}\text { Neck } \\
\left(\mathrm{cfu} / \mathrm{cm}^{2}\right)\end{array}$ & $\begin{array}{c}\text { Chest } \\
\left(\mathrm{cfu} / \mathrm{cm}^{2}\right)\end{array}$ & $\begin{array}{c}\text { Abdomen } \\
\left(\mathrm{cfu} / \mathrm{cm}^{2}\right)\end{array}$ & $\begin{array}{l}\text { Lumbar } \\
\text { Spine } \\
\left(\mathrm{cfu} / \mathrm{cm}^{2}\right)\end{array}$ & $\underset{\left(\mathrm{cfu} / \mathrm{cm}^{2}\right)}{\operatorname{Hip}}$ \\
\hline 1 & 48 & $\mathrm{~F}$ & $3.6 \times 10^{5}$ & $3.0 \times 10^{5}$ & $1.0 \times 10^{3}$ & $2.3 \times 10^{3}$ & $1.8 \times 10^{4}$ & $8.4 \times 10^{2}$ \\
\hline 2 & 31 & $M$ & $2.3 \times 10^{5}$ & $8.5 \times 10^{5}$ & $6.5 \times 10^{2}$ & $1.2 \times 10^{2}$ & $1.0 \times 10^{5}$ & $5.0 \times 10^{0}$ \\
\hline 3 & 27 & $\mathrm{~F}$ & $6.8 \times 10^{3}$ & $1.1 \times 10^{2}$ & $7.2 \times 10^{0}$ & $6.0 \times 10^{1}$ & 0 & $1.0 \times 10^{0}$ \\
\hline 4 & 21 & $\mathrm{~F}$ & $2.0 \times 10^{3}$ & $2.1 \times 10^{2}$ & $1.1 \times 10^{1}$ & $1.5 \times 10^{1}$ & $4.3 \times 10^{2}$ & $1.2 \times 10^{2}$ \\
\hline 5 & 12 & $\mathrm{~F}$ & $6.9 \times 10^{2}$ & $6.5 \times 10^{2}$ & $1.6 \times 10^{3}$ & $7.6 \times 10^{1}$ & $1.0 \times 10^{2}$ & $6.2 \times 10^{1}$ \\
\hline 6 & 34 & $M$ & $2.7 \times 10^{3}$ & $2.8 \times 10^{5}$ & $4.5 \times 10^{2}$ & $2.7 \times 10^{2}$ & $1.0 \times 10^{2}$ & $9.0 \times 10^{0}$ \\
\hline 7 & 30 & $\mathrm{M}$ & $3.7 \times 10^{4}$ & $3.1 \times 10^{3}$ & $4.0 \times 10^{0}$ & $3.7 \times 10^{3}$ & $3.3 \times 10^{4}$ & $9.0 \times 10^{0}$ \\
\hline 8 & 27 & F & $6.8 \times 10^{3}$ & $9.0 \times 10^{2}$ & $4.0 \times 10^{0}$ & $3.0 \times 10^{1}$ & 0 & $1.0 \times 10^{0}$ \\
\hline 9 & 28 & M & $4.0 \times 10^{4}$ & $2.3 \times 10^{5}$ & $1.9 \times 10^{2}$ & $2.0 \times 10^{1}$ & $2.8 \times 10^{5}$ & $5.2 \times 10^{1}$ \\
\hline 10 & 18 & F & $2.8 \times 10^{4}$ & $1.2 \times 10^{1}$ & $1.0 \times 10^{0}$ & $9.0 \times 10^{0}$ & $3.0 \times 10^{0}$ & $1.0 \times 10^{0}$ \\
\hline Mean & 27.6 & & $7.2 \times 10^{4}$ & $1.7 \times 10^{4}$ & $3.3 \times 10^{2}$ & $6.6 \times 10^{2}$ & $4.4 \times 10^{4}$ & $1.1 \times 10^{2}$ \\
\hline
\end{tabular}

${ }^{*} 95 \%$ confidence intervals of colony counts fell within 1 log of stated values.

$\mathrm{M}=$ male; $\mathrm{F}=$ female; $\mathrm{cfu}=$ colony-forming units

possible resistance of the different $\mathrm{P}$. acnes phenotypes to antiseptics is required.

It is known that antiseptic solutions used in surgery reduce the total bacterial count of the skin surface; however, they do not render the skin or wounds sterile. ${ }^{1,12,17}$ It seems that P. acnes, which is less aerotolerant than the CoNS and usually is found in the depths of the follicle, ${ }^{3}$ escapes the effects of an antiseptic as do some of the CoNS. When skin is incised, the bleeding skin edges facilitate the transport of bacteria from the follicles into the

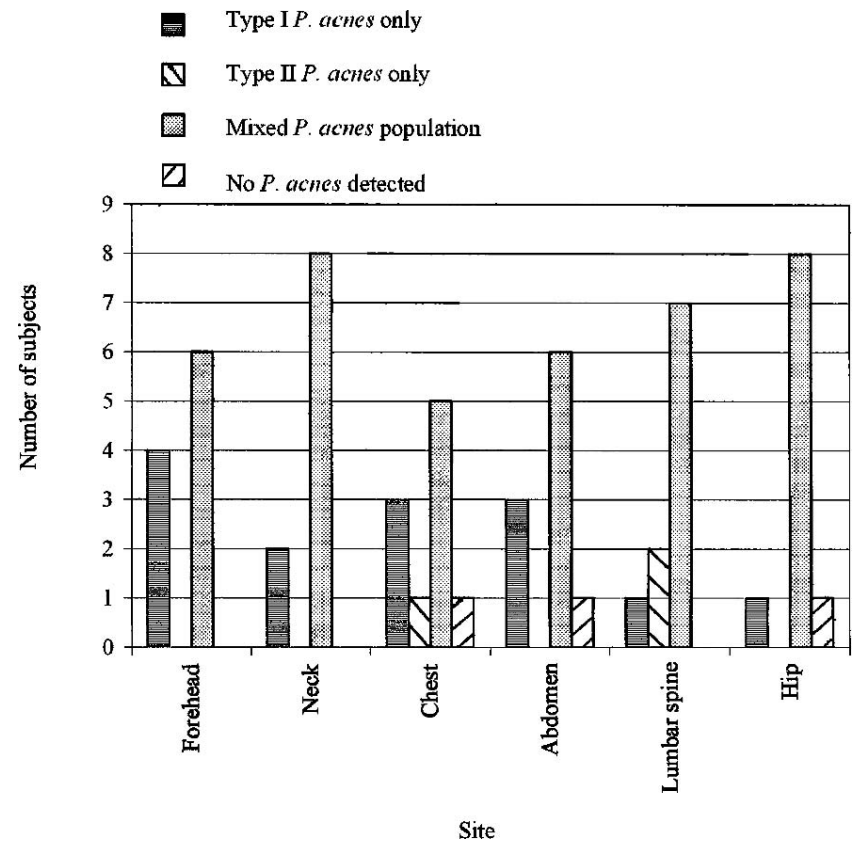

Fig 4. The number of $P$. acnes colonies detected at different sites in healthy volunteers is shown. wound. Our results confirm the presumption because P. acnes was detected more frequently than Staphylococcus spp in surgical wounds. We also showed that the wound tissue and wound washings were positive for bacterial culture less frequently than skin. The interpretation of culture results from any spinal surgical wound must be treated with caution because $29.1 \%$ of wound skin was culture positive for P. acnes or CoNS. Staphylococcus aureus does not seem to cause substantial bacterial contamination of surgical wounds; authors of other studies failed to detect it at all. ${ }^{7,25}$

In contrast with the detection of biofilm-associated prosthetic joint infection, in the current wound study, IFM did not increase the chance of detection of bacteria when compared with culture. ${ }^{23}$ In experiments with pure cultures in which total viable count (TVC) was compared with the limit of detection by IFM, only one or two bacteria were observed on a microscope slide well to which a $20 \mu \mathrm{L}$ drop containing approximately $400 \mathrm{cfu} / \mathrm{mL}$ of $\mathrm{P}$. acnes had been applied. This suggests that the bacteria observed in association with prosthesis biofilm are nonculturable whereas those in the wound study are viable and are present in much lower numbers. The majority of culture-positive clinical samples analyzed had fewer cfu/mL, and this explains why IFM often was negative.

Immunofluorescence microscopy has proven to be a useful tool in the detection of bacteria from failed hip prosthesis. ${ }^{23}$ Most importantly, IFM permits observation of bacteria. Large aggregates are highly suggestive of bacterial biofilm-related infection; however, single bacterial cells suggest intraoperative contamination. In the contaminated wounds we studied, bacteria typically were detected as single cells (Fig 3); however, in cases of prosthetic hip loosening, large aggregates are found (Fig 4), and this would suggest biofilm formation. 
TABLE 2. Comparison of Bacteria Isolated from Orthopaedic Wounds

\begin{tabular}{|c|c|c|c|c|c|}
\hline Study & Site & $\begin{array}{l}\text { Number of } \\
\text { Patients } \\
\text { Sampled }\end{array}$ & $\begin{array}{l}\text { Number of Patients } \\
\text { with Positive } \\
\text { Cultures (\%) }\end{array}$ & $\begin{array}{l}\text { Percentage of Positive } \\
\text { Cultures for } \\
\text { P. acnes }\end{array}$ & $\begin{array}{l}\text { Percentage of } \\
\text { Positive Cultures for } \\
\text { Staphylococcus spp }\end{array}$ \\
\hline Padgett et al ${ }^{18}$ & Hip & 138 & $42(30.4 \%)$ & $23.6 \%$ & $56.3 \%$ \\
\hline Dietz et $\mathrm{al}^{7}$ & Various* & 40 & $23(57.5 \%)$ & $24.2 \%$ & $57.6 \%$ \\
\hline Dietz et $\mathrm{al}^{7} \dagger$ & Spine & 12 & $7(58.3 \%)$ & $44.4 \%$ & $44.4 \%$ \\
\hline Stirling et $\mathrm{al}^{22}$ & Spine & 50 & $19(38.0 \%)$ & $84.2 \%$ & $10.5 \%$ \\
\hline Current Studył & Spine & 79 & $17(21.5 \%)$ & $64.7 \%$ & $23.5 \%$ \\
\hline
\end{tabular}

*Various = extremity, pelvis, spine.

$\dagger A$ subset of 12 spine wounds out of the larger group of 40 wounds is considered.

$\ddagger$ Wound tissue sample culture results expressed.

Bacterial contamination of spinal surgical wounds occurs relatively frequently. This almost certainly reflects the high numbers of resident skin microbiota in the areas where the surgical incision is made. We suggest that P. acnes cultured from spinal surgery wounds originates from the skin and not from other sources. Bacterial culture using agar and enrichment techniques do not help distinguish bacterial contamination from infection. Immunofluorescence microscopy is potentially a valuable tool in distinguishing between contamination and infection because it permits direct observation of bacterial cells.

\section{References}

1. Ariyasu RG: NakamuraT, Trousdale MD, Smith RE: Intraoperative bacterial contamination of the aqueous humor. Ophthalmic Surg 24:367-373, 1993.

2. Brook I: Pathogenicity of Propionibacterium acnes in mixed infections with facultative bacteria. J Med Microbiol 34:249-252, 1991.

3. Burkhart CG, Burkhart CN, Lehmann PF: Acne: a review of immunologic and microbiologic factors. Postgrad Med J 75:328-331, 1999.

4. Charnley J: Postoperative infection after total hip replacement with special reference to air contamination in the operating room. Clin Orthop 87:167-187, 1972.

5. Chia JK, Nakata MN: Intervertebral diskitis caused by Propionibacterium acnes: A report of four cases. Clin Infect Dis 23:643-644, 1996.

6. Crawford JJ, Sconyers JR, Moriarty JD, King RC, West JI: Bacteremia after tooth extractions studied with the aid of prereduced anaerobically sterilized culture media. Appl Microbiol 27:927-932, 1974.

7. Dietz FR, Koontz FP, Found EM, Marsh JL: The importance of positive bacterial cultures of specimens obtained during clean orthopaedic operations. J Bone Joint Surg 73A:1200-1207, 1991.

8. Eishi Y, Suga M, Ishige I, et al: Quantitative analysis of mycobacterial and propionibacterial DNA in lymph nodes of Japanese and European patients with sarcoidosis. J Clin Microbiol 40:198-204, 2002.

9. Esteban J, Calvo R, Pardeiro M, Soriano F: Nosocomial diskitis due to Propionibacterium acnes. J Hosp Infect 39:77-78, 1998.

10. Esteban J, Ramos JM, Soriano F: Clinical spectrum of infections due to Propionibacterium acnes. Clin Microbiol Infect 4:48-49, 1998.

11. Holland KT, Aldana O, Bojar RA, et al: Propionibacterium acnes and acne. Dermatology 196:67-68, 1998.

12. Hort KR, DeOrio JK: Residual bacterial contamination after surgical preparation of the foot or ankle with or without alcohol. Foot Ankle Int 23:946-948, 2002.

13. Johnson JL, Cummins CS: Cell wall composition and deoxyribonucleic acid similarities among the anaerobic coryneforms, classical propionibacteria, and strains of Arachniapropionica. J Bacteriol 109:1047-1066, 1972.

14. Kotilainen P, Merilahti-Palo R, Lehtonen OP, et al: Propionibacterium acnes isolated from sternal osteitis in a patient with SAPHO syndrome. J Rheumatol 23:1302-1304, 1996.

15. McGinley KJ, Webster GF, Leyden JJ: Regional variations of cutaneous propionibacteria. Appl Environ Microbiol 35:62-66, 1978.

16. Noble RC, Overman SB: Propionibacterium acnes osteomyelitis: Case report and review of the literature. J Clin Microbiol 25:251254, 1987.

17. Ostrander RV, Brage ME, Botte MJ: Bacterial skin contamination after surgical preparation in foot and ankle surgery. Clin Orthop 406:246-252, 2003.

18. Padgett DE, Silverman A, Sachjowicz F, et al: Efficacy of intraoperative cultures obtained during revision total hip arthroplasty. J Arthroplasty 10:420-426, 1995.

19. Patrick S, Gilpin D, Stevenson L: Detection of intra strain antigenic variation of Bacteroides fragilis surface polysaccharides by monoclonal antibody labeling. Infect Immun 67:4346-4351, 1999.

20. Perkins RE, Kundsin RB, Pratt MV, Abrahamsen I, Leibowitz HM: Bacteriology of normal and infected conjunctiva. J Clin Microbiol $1: 147-149,1975$

21. Ross JI, Snelling AM, Carnegie E, et al: Antibiotic-resistant acne: Lessons from Europe. Br J Dermatol 148:467-478, 2003.

22. Stirling A, Worthington T, Rafiq M, Lambert PA, Elliott TS: Association between sciatica and Propionibacterium acnes. Lancet 357:2024-2025, 2001.

23. Tunney MM, Patrick S, Curran MD, et al: Detection of prosthetic hip infection at revision arthroplasty by immunofluorescence microscopy and PCR amplification of the bacterial16S rRNA gene. J Clin Microbiol 37:3281-3290, 1999.

24. Tunney MM, Patrick S, Gorman S, et al: Improved detection of infection in hip replacements: A currently underestimated problem. J Bone Joint Surg 80B:568-572, 1998.

25. Wollinsky KH, Oetmnger M, Buchele M, et al: Autotransfusionbacterial contamination during hip arthroplasty and efficacy of cefuroxime prophylaxis: A randomized controlled study of 40 patients. Acta Orthop Scand 68:225-230, 1997. 